Review

\title{
Does exercise therapy improve the health-related quality of life of people with knee osteoarthritis? A systematic review and meta-analysis of randomized controlled trials
}

\author{
Ryo Tanaka ${ }^{1)^{*}}$, Junya Ozawa ${ }^{1)}$, Nobuhiro Kito ${ }^{1)}$, Hideki Moriyama ${ }^{2)}$ \\ 1) Department of Rehabilitation, Hiroshima International University: 555-36 Gakuendai, Kurose, \\ Higashi-Hiroshima, Hiroshima 739-2695, Japan \\ 2) Department of Rehabilitation Science, Graduate School of Health Sciences, Kobe University, Japan
}

\begin{abstract}
Purpose] The aim of this study was to examine the effects of exercise therapy on the health-related QOL of people with knee osteoarthritis. [Subjects] Four databases (PubMed, Cochrane Central Register of Controlled Trials, the Physiotherapy Evidence Database, and the Cumulative Index to Nursing and Allied Health Literature) were searched for randomized controlled trials that evaluated the effects of exercise therapy on health-related QOL assessed by the SF-36 for inclusion in our systematic review. The methodological qualities of the trials were assessed independently by two reviewers using the PEDro scale. Pooled analyses with a random-effects model or a fixed-effects model were used in the meta-analyses to calculate the standardized mean differences and $95 \%$ confidence intervals. [Results] Twelve studies met the inclusion criteria. Our meta-analysis provides high-quality evidence that exercise therapy increases the summary score, physical functioning score, and role-physical score of knee osteoarthritis sufferers. Our meta-analysis also provides moderate-quality evidence that the physical component summary and mental component summary scores were improved to a greater extent by exercise therapy than by control interventions. [Conclusion] Exercise therapy can improve health-related QOL, as assessed by the SF-36, of knee osteoarthritis sufferers.

Key words: Knee osteoarthritis, Exercise, Health-related quality of life
\end{abstract}

(This article was submitted Apr. 30, 2015, and was accepted Jun. 25, 2015)

\section{INTRODUCTION}

According to the Osteoarthritis Research Society International (OARSI) recommendations ${ }^{1)}$, subjects with symptomatic knee osteoarthritis (OA) might benefit from referral to a physical therapist for evaluation and instruction regarding appropriate exercises for reducing pain and improving functional capacity. Recently, there is increasing interest in gauging the comprehensive effects of OA through evaluations of quality of life $(\mathrm{QOL})^{2,3)}$. However, it has not yet been clearly stated in any clinical guidelines that exercise therapies can improve the generic health status of subjects with symptomatic knee OA. The notion that exercise therapies improve health-related QOL (HRQOL) must be substantiated with high-quality evidence to support the OARSI recommendations ${ }^{1)}$. HRQOL can be measured with disease-specific and generic health status questionnaires. Generic health status instruments, such as the Short Form

*Corresponding author. Ryo Tanaka (E-mail: r-tanaka@ hs.hirokoku-u.ac.jp)

C2015 The Society of Physical Therapy Science. Published by IPEC Inc. This is an open-access article distributed under the terms of the Creative Commons Attribution Non-Commercial No Derivatives (by-ncnd) License $<$ http://creativecommons.org/licenses/by-nc-nd/3.0/>
36 (SF-36), measure multiple aspects of health, including physical function, social function, and pain ${ }^{4)}$. Extensive results have been published in support of the psychometric properties of the SF-36, ${ }^{5}$ ). The SF-36 measures the following eight domains: physical functioning $(\mathrm{PF})$, role-physical (RP), bodily pain (BP), general health (GH), vitality (VT), social functioning (SF), role emotional (RE), and mental health $(\mathrm{MH})^{4)}$. The PF, RP, BP, and GH scores are the strongest measures of physical health (i.e., these scores have the greatest weights in the calculation of the physical component summary score (PCS)), and the VT, SF, RE, and MH scores are the strongest measures of mental health (i.e., they have the greatest weights in the calculation of the mental component summary score (MCS) $)^{7}$ ). In the field of knee OA, several randomized controlled trials (RCTs) investigating the effects of exercise on improvements in HRQOL, as assessed by the SF-36, have been performed. Although the effects of exercise therapies on pain, muscle strength, and physical function are supported by the results of meta-analysis ${ }^{8-10)}$, no systematic reviews with meta-analyses of RCTs that have investigated the effects of exercise therapy on the HRQOL of subjects with knee OA have yet been published. The purpose of this systematic review was to search for evidence related to improvements in HRQOL due to exercise therapy in subjects with knee OA as measured by the SF-36. 


\section{SUBJECTS AND METHODS}

Studies were included in this review if they met the following criteria: (1) the participants had knee OA, (2) the intervention was either exercise or exercise therapy, (3) the controls were either no intervention or a psycho-educational intervention, (4) the researchers assessed HRQOL using the SF-36, (5) an RCT design was used, and (6) the paper was written in English. Studies were excluded according to the following criteria: (1) the participants had hip OA or rheumatic disease, (2) the subjects had undergone total knee arthroplasty, (3) the intervention included intra-articular injections (e.g., sodium hyaluronate), (4) sufficient data for the synthesis of the results were not reported, or (5) the researchers used the SF-8 or SF-12. Paper titles and abstracts were screened using the inclusion and exclusion criteria. After screening, two authors read the full text of the articles to determine whether or not the retrieved trials met the inclusion criteria.

The following electronic databases were searched from the earliest date available until the 31 st of January 2014: PubMed, the Cochrane Central Register of Controlled Trials (CENTRAL), the Physiotherapy Evidence Database (PEDro), and the Cumulative Index to Nursing and Allied Health Literature (CINAHL). Manual scanning of the reference lists of the included studies and previous systematic reviews was also conducted to ensure that all of the relevant trials were identified. The search strategy (Table 1) was a combination of free text words and Medical Subject Headings $(\mathrm{MeSH})$ terms.

All trials were independently critically appraised for methodological quality by two reviewers (R.T. and J.O.) using the PEDro scale ${ }^{11)}$. Standardized mean differences (SMDs) and 95\% confidence intervals (CIs) were calculated from the post-intervention means and standard deviations (SDs). If the post-intervention scores were not reported, changes in the scores were used for the synthesis of the results. Meta-analyses were performed with a random-effects model or a fixed-effects model for outcomes that used inverse variance methods (RevMan, version 5.1). Statistical heterogeneity was assessed using the $I^{2}$ statistic; values of $>25 \%$ represent substantial levels of heterogeneity ${ }^{12)}$. To assess the risk of publication bias, funnel plots were drawn if there were $\geq 10$ trials in a meta-analysis (tests for funnel plot asymmetry only have sufficient power when there are $\geq 10$ trials) ${ }^{13)}$. The Grading of Recommendations Assessment, Development and Evaluation (GRADE) approach ${ }^{14)}$ was applied to each meta-analysis performed to determine the quality of the evidence.

\section{RESULTS}

The database search yielded a total of 843 studies. Six additional studies were identified by scanning the references and citation tracking. After removal of the duplicates, the titles and abstracts of 438 studies were screened. Full-text copies of 17 trials were retrieved for closer examination. Of these, five were excluded, and consensus was reached on including a total of 12 trials in the review (Fig. 1).

The 12 trials involved 1,239 participants. The available
Table 1. Search strategy

\begin{tabular}{ll}
\hline (1) PubMed & $\# 1$ osteoarthritis, knee[MeSH Terms] \\
& $\# 2$ exercise[MeSH Terms] \\
& $\# 3$ exercise therapy[MeSH Terms] \\
& $\# 4$ (\#1 AND (\#2 OR \#3)) \\
& Limits: Randomized Controlled Trial \\
(2) CENTRAL & $\# 1$ osteoarthritis, knee[MeSH Terms] \\
& $\# 2$ exercise[MeSH Terms] \\
& $\# 3$ exercise therapy[MeSH Terms] \\
& $\# 4$ (\#1 AND (\#2 OR \#3)) \\
& $\bullet$ Advance search \\
(3) PEDro & Title or Abstract: osteoarthritis, knee, exercise \\
& Method: clinical trial \\
(4) CINAHL & $\# 1$ osteoarthritis, knee[MeSH Terms] \\
& $\# 2$ exercise[MeSH Terms] \\
& $\# 3$ therapeutic exercise[MeSH Terms] \\
& $\# 4$ (\#1 AND (\#2 OR \#3)) \\
& Limits: Randomized Controlled Trial
\end{tabular}

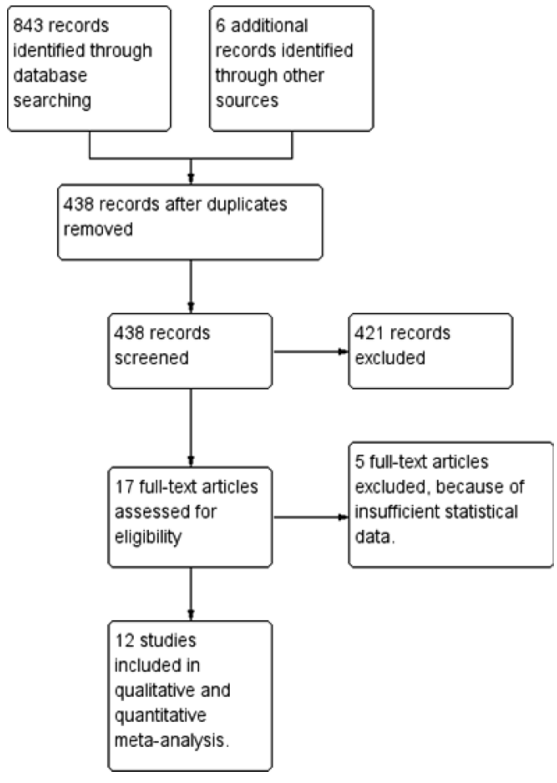

Fig. 1. Study flow diagram

data for the exercise groups indicated that the mean ages and female ratios across all studies ranged from 54.8 to $70.2 \%$ and 50 to $100 \%$, respectively (Table 2). The trials included in our study used muscle strengthening exercises with or without weight bearing, walking, balance exercises, muscle stretching exercises, Tai chi exercises, Baduanjin, or functional exercises. The SF-36 versions that were used were in English, Turkish, Japanese, and Korean (Table 3).

The results of the individual studies and synthesis of the results are shown in Table 4. Among the 12 trials $^{15-26)}$ included in our study, the data of Aglamis et al. ${ }^{16)}$ were not included in the synthesis of the results for physical function, body pain, mental health, vitality, or general health, because their scores at baseline were already significantly higher in the exercise group than in the control group. The 
Table 2. Summary of included trials (participants' characteristics and intervention)

\begin{tabular}{|c|c|c|c|c|c|c|}
\hline Study & $\begin{array}{l}\text { Participants } \\
\text { (Exercise group) }\end{array}$ & $\begin{array}{l}\text { Participants } \\
\text { (Control group) }\end{array}$ & Exercise intervention & $\begin{array}{l}\text { Frequency } \\
\text { (per week) }\end{array}$ & $\begin{array}{c}\text { Duration } \\
\text { (weeks) }\end{array}$ & $\begin{array}{c}\text { PEDro } \\
\text { score }\end{array}$ \\
\hline $\begin{array}{l}\text { Aglamis } \\
\text { et al. } \\
2009\end{array}$ & $\begin{array}{l}\mathrm{n}=16 \\
\text { Age }(\mathrm{yrs})=56.8(4) \\
\text { Female }(\%)=100\end{array}$ & $\begin{array}{l}\mathrm{n}=9 \\
\text { Age }(\mathrm{yrs})=54.4(12) \\
\text { Female }(\%)=100\end{array}$ & $\begin{array}{l}\text { Aerobic, functional strengthening, and flex- } \\
\text { ibility exercises }\end{array}$ & 3 & 12 & 3 \\
\hline $\begin{array}{l}\text { An et al. } \\
2008\end{array}$ & $\begin{array}{l}\mathrm{n}=14 \\
\text { Age }(\mathrm{yrs})=65.4(8.2) \\
\text { Female }(\%)=100\end{array}$ & $\begin{array}{l}\mathrm{n}=14 \\
\text { Age }(\mathrm{yrs})=64.6(6.7) \\
\text { Female }(\%)=100\end{array}$ & Baduanjin & 5 & 8 & 4 \\
\hline $\begin{array}{l}\text { Baker et } \\
\text { al. } 2001\end{array}$ & $\begin{array}{l}\mathrm{n}=23 \\
\text { Age }=69(6) \\
\text { Female }(\%)=73.9\end{array}$ & $\begin{array}{l}\mathrm{n}=23 \\
\text { Age }=68(6) \\
\text { Female }(\%)=82.6\end{array}$ & $\begin{array}{l}\text { Two functional exercises (squats and step- } \\
\text { ups) }\end{array}$ & 3 & 16 & 7 \\
\hline $\begin{array}{l}\text { Brosseau } \\
\text { et al. } \\
2012\end{array}$ & $\begin{array}{l}\mathrm{n}=79 \\
\text { Age }=63.9(10.3) \\
\text { Female }(\%)=69.9\end{array}$ & $\begin{array}{l}\mathrm{n}=74 \\
\text { Age }=62.3(6.8) \\
\text { Female }(\%)=63.5\end{array}$ & Walking & 3 & 48 & 4 \\
\hline $\begin{array}{l}\text { Doi et al. } \\
2008\end{array}$ & $\begin{array}{l}\mathrm{n}=71 \\
\text { Age }(\mathrm{yrs})=66.8(12.8) \\
\text { Female }(\%)=77.5\end{array}$ & $\begin{array}{l}\mathrm{n}=70 \\
\text { Age }(\mathrm{yrs})=68.9(21.1) \\
\text { Female }(\%)=74.6\end{array}$ & Quadriceps strengthening exercises & 7 & 8 & 6 \\
\hline $\begin{array}{l}\text { Fransen } \\
\text { et al. } \\
2001\end{array}$ & $\begin{array}{l}\text { Group } 1 \\
\mathrm{n}=43 \\
\text { Age }(\mathrm{yrs})=68.5(8.7) \\
\text { Female }(\%)=74 \\
\text { Group } 2 \\
\mathrm{n}=40 \\
\text { Age }(\mathrm{yrs})=65.3(7.1) \\
\text { Female }(\%)=78\end{array}$ & $\begin{array}{l}\mathrm{n}=43 \\
\text { Age }(\mathrm{yrs})=66.1(10.3) \\
\text { Female }(\%)=67\end{array}$ & $\begin{array}{l}\text { Group 1: The choice, frequency, and dura- } \\
\text { tion of individual treatments at the discre- } \\
\text { tion of the treating physical therapist } \\
\text { Group 2: Quadriceps muscle strengthening } \\
\text { exercise, stretching, aerobic exercise, and } \\
\text { patella taping }\end{array}$ & 2 & 8 & 7 \\
\hline $\begin{array}{l}\text { Lee et al. } \\
2009\end{array}$ & $\begin{array}{l}\mathrm{n}=29 \\
\text { Age }(\mathrm{yrs})=70.2(4.8) \\
\text { Female }(\%)=93\end{array}$ & $\begin{array}{l}\mathrm{n}=15 \\
\text { Age }(\mathrm{yrs})=66.9(6.0) \\
\text { Female }(\%)=93\end{array}$ & Tai Chi exercise & 2 & 8 & 8 \\
\hline $\begin{array}{l}\text { Lim et al. } \\
2010\end{array}$ & $\begin{array}{l}\text { Group } 1 \\
\mathrm{n}=26 \\
\text { Age }(\mathrm{yrs})=65.7(8.9 \\
\text { Female }(\%)=88.5 \\
\text { Group } 2 \\
\mathrm{n}=25 \\
\text { Age }(\mathrm{yrs})=67.7(7.7) \\
\text { Female }(\%)=84\end{array}$ & $\begin{array}{l}\mathrm{n}=24 \\
\text { Age }(\mathrm{yrs})=63.3(5.3) \\
\text { Female }(\%)=87.5\end{array}$ & $\begin{array}{l}\text { Group 1: aquatic exercise (in water, forward, } \\
\text { backward, and side walking; underwater } \\
\text { bicycling; strength training; fast walking } \\
\text { with swinging arms; and aqua running) } \\
\text { Group 2: land-based exercise (joint mobi- } \\
\text { lization; strengthening exercises, range-of- } \\
\text { motion exercise; stretching exercises; and } \\
\text { bicycling) }\end{array}$ & 3 & 8 & 7 \\
\hline $\begin{array}{l}\text { O'Reilly } \\
\text { et al. } \\
1999\end{array}$ & $\begin{array}{l}\mathrm{n}=78 \\
\mathrm{Age}=61.9(10.0)\end{array}$ & $\begin{array}{l}\mathrm{n}=113 \\
\mathrm{Age}=62.2(9.7)\end{array}$ & $\begin{array}{l}\text { Isometric quadriceps contraction, isotonic } \\
\text { quadriceps contraction, isotonic hamstring } \\
\text { contraction, and dynamic stepping exercise }\end{array}$ & 7 & 24 & 7 \\
\hline $\begin{array}{l}\text { Rejeski et } \\
\text { al. } 2002\end{array}$ & $\begin{array}{l}\text { Group } 1 \\
\mathrm{n}=69 \\
\text { Age }=69.0(6.6) \\
\text { Female }(\%)=73.8 \\
\text { Group } 2 \\
\mathrm{n}=68 \\
\text { Age }=68.5(5.6) \\
\text { Female }(\%)=73.3\end{array}$ & $\begin{array}{l}\mathrm{n}=68 \\
\text { Age }=68.6(6.3) \\
\text { Female }(\%)=66.7\end{array}$ & $\begin{array}{l}\text { Group 1: Exercise only (aerobic phase, } \\
\text { resistance-training phase, second aerobic } \\
\text { phase, cool-down phase) } \\
\text { Group 2: Exercise + diet }\end{array}$ & 3 & 72 & 6 \\
\hline $\begin{array}{l}\text { Salli et } \\
\text { al. } 2010\end{array}$ & $\begin{array}{l}\text { Group } 1 \\
\mathrm{n}=25 \\
\text { Age }(\mathrm{yrs})=55.7(8.2) \\
\text { Female }(\%)=82.6 \\
\text { Group } 2 \\
\mathrm{n}=25 \\
\text { Age }(\mathrm{yrs})=57.1(6.8) \\
\text { Female }(\%)=83.3\end{array}$ & $\begin{array}{l}\mathrm{n}=25 \\
\text { Age }(\mathrm{yrs})=58.3(6.7) \\
\text { Female }(\%)=79.2\end{array}$ & $\begin{array}{l}\text { Group 1: Combined concentric-eccentric } \\
\text { exercise } \\
\text { Group 2: Isometric exercise (progressive) }\end{array}$ & 3 & 8 & 6 \\
\hline $\begin{array}{l}\text { Thor- } \\
\text { stensson } \\
\text { et al. } \\
2005\end{array}$ & $\begin{array}{l}\mathrm{n}=30 \\
\text { Age }(\mathrm{yrs})=54.8(7.1) \\
\text { Female }(\%)=50\end{array}$ & $\begin{array}{l}\mathrm{n}=31 \\
\text { Age }(\mathrm{yrs})=57.3(4.7) \\
\text { Female }(\%)=50\end{array}$ & $\begin{array}{l}\text { Weight-bearing exercises, endurance, and } \\
\text { lower limb strength }\end{array}$ & 2 & 6 & 6 \\
\hline
\end{tabular}


Table 3. Summary of included trials (instrumental information)

\begin{tabular}{lcccc}
\hline Study & $\begin{array}{c}\text { The SF-36 } \\
\text { version }\end{array}$ & Calculated scale & $\begin{array}{c}\text { Pooled score } \\
\text { in our meta-analysis }\end{array}$ & $\begin{array}{c}\text { Significantly deference } \\
\text { between groups in baseline }\end{array}$ \\
\hline Aglamis et al. 2009 & Turkish & Eight scales & Change scores & PF, BP, GH, VT, and MH \\
An et al. 2008 & English & GH, SF, and MH & Postintervention scores & None \\
Baker et al. 2001 & English & Eight scales & Postintervention scores & Unkown \\
Brosseau et al. 2012 & English & PCS, MCS, and 8 scales & Postintervention scores & Unkown \\
Doi et al. 2008 & Japanese & Summary & Postintervention scores & None \\
Fransen et al. 2001 & English & PCS and MCS & Change scores & Unkown \\
Lee et al. 2009 & English & Summary, PCS, and MCS & Postintervention scores & None \\
Lim et al. 2010 & Korean & PCS and MCS & Postintervention scores & None \\
O'Reilly et al. 1999 & English & Eight scales & Change scores & Unkown \\
Rejeski et al. 2002 & English & PCS, MCS, and 8 scales & Postintervention scores & Unkown \\
Salli et al. 2010 & Turkish & PCS and MCS & Postintervention scores & None \\
Thorstensson et al. 2005 & English & PCS and MCS & Change scores & None \\
\hline
\end{tabular}

PF: physical functioning, BP: bodily pain, GH: general health, VT: vitality, SF: social functioning, MH: mental health

Table 4. Meta-analysis of the effect of exercise therapy on HRQOL (SF-36)

\begin{tabular}{|c|c|c|c|c|c|c|}
\hline & $\begin{array}{c}\text { No. of trials } \\
\text { (exercise groups) }\end{array}$ & $\begin{array}{l}\text { Ratio of trials } \\
(\text { PEDro }<6)\end{array}$ & $\begin{array}{c}\text { No. of } \\
\text { participants }\end{array}$ & SMD $[95 \% \mathrm{CI}]$ & $r^{2}$ & $\begin{array}{c}\text { Quality of the } \\
\text { evidence } \\
\text { (GRADE) }\end{array}$ \\
\hline Summary & $2(2)$ & $0 \%$ & 165 & $0.47[0.16,0.78]$ & $0 \%$ & High \\
\hline Physical component summary & $7(10)$ & $14 \%$ & 771 & $0.52[0.21,0.83]$ & $76 \%$ & Moderate $\S$ \\
\hline Mental component summary & $7(10)$ & $14 \%$ & 771 & $0.44[0.12,0.75]$ & $77 \%$ & Moderate§ \\
\hline Physical functioning & $4(5)$ & $25 \%$ & 587 & $0.28[0.12,0.45]$ & $0 \%$ & High \\
\hline Role physical & $4(5)$ & $25 \%$ & 587 & $0.26[0.10,0.43]$ & $19 \%$ & High \\
\hline Bodily pain & $4(5)$ & $25 \%$ & 587 & $0.22[-0.04,0.47]$ & $55 \%$ & Moderate§ \\
\hline General health & $5(6)$ & $40 \%$ & 608 & $0.15[-0.01,0.31]$ & $6 \%$ & High \\
\hline Vitality & $4(5)$ & $25 \%$ & 587 & $0.09[-0.07,0.26]$ & $0 \%$ & High \\
\hline Social functioning & $5(6)$ & $40 \%$ & 608 & $0.17[-0.08,0.43]$ & $54 \%$ & Moderate§ \\
\hline Role emotional & $4(5)$ & $25 \%$ & 587 & $0.07[-0.10,0.23]$ & $0 \%$ & High \\
\hline Mental health & $5(6)$ & $40 \%$ & 608 & $0.15[-0.08,0.37]$ & $41 \%$ & Moderate§ \\
\hline
\end{tabular}

$\S$ Reason for downgrade: Statistical heterogeneity $\left(I^{2}>25 \%\right)$

results of our meta-analysis provided high-quality evidence that exercise therapy increased the summary score, PF score and RP scores of knee OA sufferers. Our meta-analysis also provided moderate-quality evidence that the physical component summary and mental component summary scores were improved to a greater extent by exercise therapy than by control interventions.

\section{DISCUSSION}

Using disease-specific instruments, previous systematic reviews have confirmed the effects of exercise therapy on pain and physical function of subjects with knee $\mathrm{OA}^{27)}$. The Western Ontario McMasters University arthritis index (WOMAC) comprises three subscales that evaluate pain, physical function, and stiffness, and positive changes in WOMAC scores reflect improvements in these problems. Our data show that the score of not only the WOMAC but also the SF-36, which is not a disease-specific instrument, were improved by exercise therapy. The reason for these findings might be that, like the WOMAC, the SF-36 includes domains concerned with physical function. The scores for not only the PF but also RP increased to greater degrees in the exercise groups than in the control groups, and this evidence was judged to be of high quality. Our results confirmed that exercise therapy is mildly to moderately effective at improving the generic health status of subjects with knee OA in terms of the physical components. Regarding the development of practice guidelines, these findings will be useful for the recommendation of exercise therapy for improving HRQOL. These findings also provide a solid platform for the development of further studies.

Our results also show that the MCS scores were significantly higher in the exercise therapy groups than in the controls. The MCS score were significantly higher in the intervention groups, but the scores on the $\mathrm{MH}, \mathrm{RE}, \mathrm{SF}$, and VT scales (particularly the VT and RE scales) were not different. There were differences among the studies regarding the choice of the outcome measures, MCS, MH, RE, VT, and $\mathrm{SF}$, and these differences affected our findings. In three ${ }^{21-23)}$ 
of the four studies in which only the MCS was reported, the standard mean difference in the MCS was moderate to very high. Although scale-level data were not available for these three studies, it is likely that both the VT and RE improved because the MCSs substantially improved. Conversely, in the two studies ${ }^{24,26)}$ which reported both VT, RE and MCS data, none of the scales improved much. In the former three studies, the exercise intervention durations were 8 weeks. In contrast, the exercise intervention durations were 48 to 72 weeks in the latter studies, which represented a more than 6-fold increase compared to the former three studies. This difference in the length of the exercise interventions might explain these results.

The efficacies of exercise improving HRQOL, especially with regard to physical component of subjects with knee $\mathrm{OA}$, are supported by the results of our meta-analysis. The results of our present study suggest that clinicians should make use of the strong evidence to choose exercise therapies to improve HRQOL of subjects with knee OA.

Our study has two strengths. First, the SF-36 data from multiple studies were synthesized. Evidence regarding the effect of exercise therapy has not previously been based on generic health status instruments ${ }^{27-29)}$. However, SF-36 is a generic health status instrument ${ }^{4}$ ). Although some of the studies used translations of the SF-36 (Turkish, Japanese, and Korean), these versions have been tested for their validity and reliability ${ }^{30-32)}$. It is important to confirm that exercise therapy can effectively improve global HRQOL, including mental health, rather than only influencing disease-specific domains. Our study's second strength was that the quantitative effect of exercise on HRQOL was clarified by performing a meta-analysis. Thus, comparisons of the effects of exercise therapy with the effects of other interventions on HRQOL scores became possible. Such comparisons will be useful for the selection of treatment methods.

Our study had several limitations. First, dissimilar protocol designs were employed in the trials. The exercise intensities, session durations, and numbers of sets were not always similar among the trials. Although the SMD was used as the summary measure, high statistical heterogeneity was observed in both the PCS and MCS. Because the reasons for these high heterogeneities could not be determined, the effect size should only be used as a reference. Future metaanalyses of RCTs with similar exercise protocols should be performed to decrease the variance of the effects at the study level. The second limitation was publication bias. According to the Cochrane handbook for systematic reviews of interventions ${ }^{33)}$, tests for funnel plot asymmetry, which indicates the presence of publication bias, should only be performed when at least 10 studies have been included in the meta-analysis because fewer studies result in a test power that is too low to distinguish chance from real asymmetry. The presence of publication bias could not be determined, because the number of studies included in our meta-analysis was too small to perform this test. If publication bias were recognized and eliminated in future systematic reviews using Egger's test, it is probable that the pooled effect size for HRQOL would be smaller than that observed in present data. Another limitation was trials that used the SF-36 were collected to confirm the effect of exercise therapy on HRQOL, and trials that used other instruments were excluded. A comparison of the orthopaedic literature from 1991 with that from 2001 suggested that the tool most commonly used to determine the patients' perspectives was the SF-36 ${ }^{34)}$. Additionally, a systematic review performed by Veenhof et al. suggested that the most appropriate questionnaires for patients with hip and/or knee OA seem to be the condition-specific questionnaire WOMAC and the generic questionnaire SF-36 ${ }^{35)}$. Therefore, this limitation probably did not affect our results to a measurable degree.

In conclusion, this systematic review demonstrated that exercise therapy can improve HRQOL, as assessed by the SF-36, of knee OA sufferers. However, this review failed to clarify whether the effect sizes of exercise therapies on HRQOL, particularly the PCS and MCS, are influenced by dissimilar protocol designs among trials or by publication bias.

\section{REFERENCES}

1) Zhang W, Moskowitz RW, Nuki G, et al.: OARSI recommendations for the management of hip and knee osteoarthritis, Part II: OARSI evidencebased, expert consensus guidelines. Osteoarthritis Cartilage, 2008, 16: 137-162. [Medline] [CrossRef]

2) Peungsuwan P, Sermcheep P, Harnmontree P, et al.: The effectiveness of Thai exercise with traditional massage on the pain, walking ability and QOL of older people with knee osteoarthritis: a randomized controlled trial in the community. J Phys Ther Sci, 2014, 26: 139-144. [Medline] [CrossRef]

3) Wi S, Kang J, Jang J: Clinical feasibility of exercise game for depression treatment in older women with osteoarthritis: a pilot study. J Phys Ther Sci, 2013, 25: 165-167. [CrossRef]

4) Ware JE Jr, Sherbourne CD: The MOS 36-item short-form health survey (SF-36). I. Conceptual framework and item selection. Med Care, 1992, 30: 473-483. [Medline] [CrossRef]

5) Ware JE Jr, Keller SD, Hatoum HT, et al.: The SF-36 Arthritis-Specific Health Index (ASHI): I. Development and cross-validation of scoring algorithms. Med Care, 1999, 37: MS40-MS50. [Medline] [CrossRef]

6) Keller SD, Ware JE Jr, Hatoum HT, et al.: The SF-36 Arthritis-Specific Health Index (ASHI): II. Tests of validity in four clinical trials. Med Care, 1999, 37: MS51-MS60. [Medline] [CrossRef]

7) Ware J, Kosinski M: SF-36 Physical and Mental Health Summary Scales: A manual for users of Version 1, 2nd ed. QualityMetric Incorporated, 2004.

8) Pisters MF, Veenhof C, van Meeteren NL, et al.: Long-term effectiveness of exercise therapy in patients with osteoarthritis of the hip or knee: a systematic review. Arthritis Rheum, 2007, 57: 1245-1253. [Medline] [CrossRef]

9) Devos-Comby L, Cronan T, Roesch SC: Do exercise and self-management interventions benefit patients with osteoarthritis of the knee? A metaanalytic review. J Rheumatol, 2006, 33: 744-756. [Medline]

10) Lange AK, Vanwanseele B, Fiatarone Singh MA: Strength training for treatment of osteoarthritis of the knee: a systematic review. Arthritis Rheum, 2008, 59: 1488-1494. [Medline] [CrossRef]

11) de Morton NA: The PEDro scale is a valid measure of the methodological quality of clinical trials: a demographic study. Aust J Physiother, 2009, 55 : 129-133. [Medline] [CrossRef]

12) Higgins JP, Thompson SG, Deeks JJ, et al.: Measuring inconsistency in meta-analyses. BMJ, 2003, 327: 557-560. [Medline] [CrossRef]

13) Sterne JA, Egger M, Moher D: Addressing reporting biases. In: Higgins JPT and Green S (eds), Cochrane Handbook for Systematic Reviews of Interventions. West Sussex, Wiley-Blackwell, 2008, pp 297-333.

14) Atkins D, Best D, Briss PA, et al. GRADE Working Group: Grading quality of evidence and strength of recommendations. BMJ, 2004, 328: 1490. [Medline] [CrossRef]

15) An B, Dai K, Zhu Z, et al.: Baduanjin alleviates the symptoms of knee osteoarthritis. J Altern Complement Med, 2008, 14: 167-174. [Medline] [CrossRef]

16) Aglamiş B, Toraman NF, Yaman H: Change of quality of life due to exercise training in knee osteoarthritis: SF-36 and WOMAC. J Back Musculoskeletal Rehabil, 2009, 22: 43-45, 47-48, 46. [Medline] 
17) Doi T, Akai M, Fujino K, et al.: Effect of home exercise of quadriceps on knee osteoarthritis compared with nonsteroidal antiinflammatory drugs: a randomized controlled trial. Am J Phys Med Rehabil, 2008, 87: 258-269. [Medline] [CrossRef]

18) Lim JY, Tchai E, Jang SN: Effectiveness of aquatic exercise for obese patients with knee osteoarthritis: a randomized controlled trial. PM R, 2010, 2: 723-731, quiz 793. [Medline] [CrossRef]

19) Baker KR, Nelson ME, Felson DT, et al.: The efficacy of home based progressive strength training in older adults with knee osteoarthritis: a randomized controlled trial. J Rheumatol, 2001, 28: 1655-1665. [Medline]

20) Thorstensson CA, Roos EM, Petersson IF, et al.: Six-week high-intensity exercise program for middle-aged patients with knee osteoarthritis: a randomized controlled trial [ISRCTN20244858]. BMC Musculoskelet Disord, 2005, 6: 27. [Medline] [CrossRef]

21) Fransen M, Crosbie J, Edmonds J: Physical therapy is effective for patients with osteoarthritis of the knee: a randomized controlled clinical trial. J Rheumatol, 2001, 28: 156-164. [Medline]

22) Lee HJ, Park HJ, Chae Y, et al.: Tai Chi Qigong for the quality of life of patients with knee osteoarthritis: a pilot, randomized, waiting list controlled trial. Clin Rehabil, 2009, 23: 504-511. [Medline] [CrossRef]

23) Salli A, Sahin N, Baskent A, et al.: The effect of two exercise programs on various functional outcome measures in patients with osteoarthritis of the knee: A randomized controlled clinical trial. Isokinet Exerc Sci, 2010, 18: 201-209.

24) Rejeski WJ, Focht BC, Messier SP, et al.: Obese, older adults with knee osteoarthritis: weight loss, exercise, and quality of life. Health Psychol, 2002, 21: 419-426. [Medline] [CrossRef]

25) O'Reilly SC, Muir KR, Doherty M: Effectiveness of home exercise on pain and disability from osteoarthritis of the knee: a randomised controlled trial. Ann Rheum Dis, 1999, 58: 15-19. [Medline] [CrossRef]

26) Brosseau L, Wells GA, Kenny GP, et al.: The implementation of a community-based aerobic walking program for mild to moderate knee osteoar- thritis: a knowledge translation randomized controlled trial: part II: clinical outcomes. BMC Public Health, 2012, 12: 1073. [Medline] [CrossRef]

27) Fransen M, McConnell S: Exercise for osteoarthritis of the knee. Cochrane Database Syst Rev, 2008, 4: CD004376. [Medline]

28) Tanaka R, Ozawa J, Kito N, et al.: Effect of the frequency and duration of land-based therapeutic exercise on pain relief for people with knee osteoarthritis: a systematic review and meta-analysis of randomized controlled trials. J Phys Ther Sci, 2014, 26: 969-975. [Medline] [CrossRef]

29) Ye J, Cai S, Zhong W, et al.: Effects of tai chi for patients with knee osteoarthritis: a systematic review. J Phys Ther Sci, 2014, 26: 1133-1137. [Medline] [CrossRef]

30) Tüzün EH, Eker L, Aytar A, et al.: Acceptability, reliability, validity and responsiveness of the Turkish version of WOMAC osteoarthritis index. Osteoarthritis Cartilage, 2005, 13: 28-33. [Medline] [CrossRef]

31) Fukuhara S, Bito $\mathrm{S}$, Green J, et al.: Translation, adaptation, and validation of the SF-36 Health Survey for use in Japan. J Clin Epidemiol, 1998, 51: 1037-1044. [Medline] [CrossRef]

32) Han CW, Lee EJ, Iwaya T, et al.: Development of the Korean version of Short-Form 36-Item Health Survey: health related QOL of healthy elderly people and elderly patients in Korea. Tohoku J Exp Med, 2004, 203: 189194. [Medline] [CrossRef]

33) Deeks JJ, Higgins JP, Altman DG: Analysing data and undertaking metaanalyses. In: Higgins JPT and Green S (eds), Cochrane Handbook for Systematic Reviews of Interventions. West Sussex, Wiley-Blackwell, 2008, pp 243-296.

34) Beaton DE, Schemitsch E: Measures of health-related quality of life and physical function. Clin Orthop Relat Res, 2003, (413): 90-105. [Medline] [CrossRef]

35) Veenhof C, Bijlsma JW, van den Ende CH, et al.: Psychometric evaluation of osteoarthritis questionnaires: a systematic review of the literature. Arthritis Rheum, 2006, 55: 480-492. [Medline] [CrossRef] 